
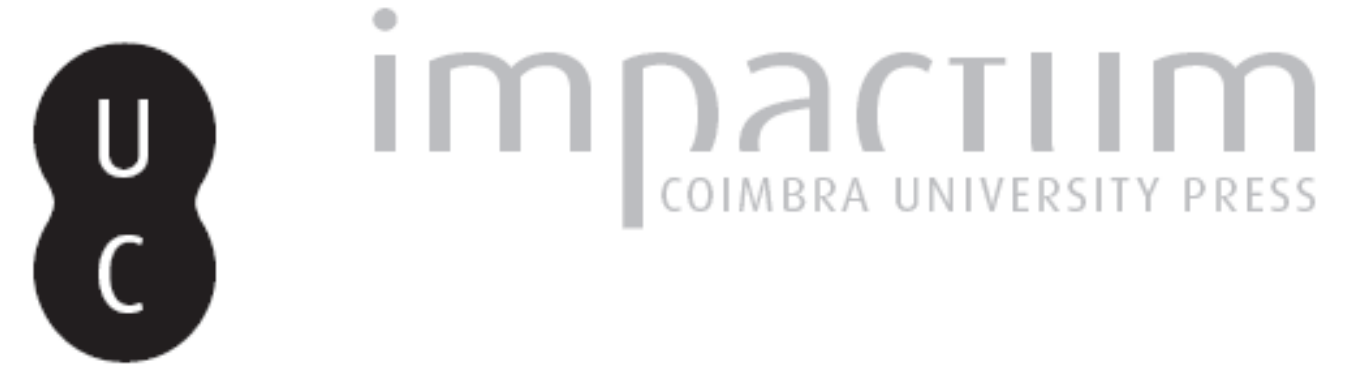

\title{
O papel da perceção e comunicação na mitigação do risco de terramoto
}

\author{
Autor(es): $\quad$ Maio, Rui; Ferreira, Tiago M.; Vicente, Romeu
}

Publicado por: Imprensa da Universidade de Coimbra

URL persistente:

URI:http://hdl.handle.net/10316.2/44192

DOI:

DOI:https://doi.org/10.14195/1647-7723_25-2_6

Accessed : $\quad$ 26-Apr-2023 14:20:22

A navegação consulta e descarregamento dos títulos inseridos nas Bibliotecas Digitais UC Digitalis, UC Pombalina e UC Impactum, pressupõem a aceitação plena e sem reservas dos Termos e Condições de Uso destas Bibliotecas Digitais, disponíveis em https://digitalis.uc.pt/pt-pt/termos.

Conforme exposto nos referidos Termos e Condições de Uso, o descarregamento de títulos de acesso restrito requer uma licença válida de autorização devendo o utilizador aceder ao(s) documento(s) a partir de um endereço de IP da instituição detentora da supramencionada licença.

Ao utilizador é apenas permitido o descarregamento para uso pessoal, pelo que o emprego do(s) título(s) descarregado(s) para outro fim, designadamente comercial, carece de autorização do respetivo autor ou editor da obra.

Na medida em que todas as obras da UC Digitalis se encontram protegidas pelo Código do Direito de Autor e Direitos Conexos e demais legislação aplicável, toda a cópia, parcial ou total, deste documento, nos casos em que é legalmente admitida, deverá conter ou fazer-se acompanhar por este aviso.

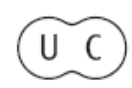




\section{O PAPEL DA PERCEÇÃO E COMUNICAÇÃO NA MITIGAÇÃO DO RISCO DE TERRAMOTO*}

THE ROLE OF PERCEPTION AND COMMUNICATION IN MITIGATING EARTHQUAKE RISK

Rui Maio

RISCO - RIscos e Sustentabilidade na COnstrução Departamento de Engenharia Civil, Universidade de Aveiro (Portugal) ORCID 0000-0001-6862-7967 ruiamaio@ua.pt

Tiago M. Ferreira

ISISE - Instituto para a Sustentabilidade e Inovação em Engenharia Estrutural Departamento de Engenharia Civil, Universidade do Minho (Portugal) ORCID 0000-0001-6454-7927 tmferreira@civil.uminho.pt

Romeu Vicente

RISCO - RIscos e Sustentabilidade na COnstrução Departamento de Engenharia Civil, Universidade de Aveiro (Portugal) ORCID 0000-0002-5456-1642 romvic@ua.pt

\section{RESUMO}

A formação e educação cívica constitui uma das mais importantes e poderosas ferramentas para uma maior consciencialização e perceção dos cidadãos para o risco sísmico, desempenhando um papel fundamental na construção de sociedades mais resilientes. No entanto, por exigir o envolvimento de todos os cidadãos sem exceção, a promoção de uma cultura de risco representa um desafio transversal à nossa sociedade. Reconhecendo a perceção de risco como um aspeto fundamental para o desenvolvimento e implementação de estratégias de informação e comunicação do risco terramoto, este artigo apresenta os resultados de uma campanha de sensibilização realizada no âmbito do projeto de investigação URBSIS que consistiu na recolha e tratamento das respostas a um questionário elaborado com o objetivo de avaliar a perceção dos cidadãos para esta problemática. O questionário teve como público alvo os residentes do Bairro Ribeirinho da cidade de Faro e a comunidade técnica local ligada, direta ou indiretamente, aos setores da construção e do planeamento urbano.

Palavras-chave: Mitigação do risco sísmico, perceção e comunicação do risco, educação para o risco.

\section{ABSTRACT}

Civic education and raising public awareness are among the most important tools for improving the awareness and perception of citizens to earthquake risk, and are essential to the construction of more resilient societies. However, since the involvement of all citizens, without exception, is required creating and embedding a risk culture is a challenge to the whole of our society. Being aware that risk perception is fundamental to developing and implementing strategies to communicate information about earthquake risk, this paper deals with earthquake risk perception and communication in Portugal and discusses the results of an awareness-raising campaign undertaken as part of the URBSIS research project. It involved gathering and processing responses to a questionnaire that aimed to assess public knowledge and awareness of earthquake risk. The questionnaire was applied to the residents of the Riverside neighborhood of Faro called Bairro Ribeirinho, and the local technical community related directly or indirectly to the construction and urban planning sectors.

Keywords: Earthquake risk mitigation, risk perception and communication, education for risk reduction.

\footnotetext{
* O texto deste artigo corresponde a uma comunicação apresentada no IV Congresso Internacional de Riscos, tendo sido submetido em 07-06-2017, sujeito a revisão por pares a 22-09-2017 e aceite para publicação em 20-12-2017. Este artigo é parte integrante da Revista Territorium, n. ${ }^{\circ} 25$ (II), 2018, ${ }^{\circ}$ RIscos, ISSN: 0872-8941.
} 


\section{Introdução}

Como é reconhecido, a mitigação do risco sísmico passa, em larga medida, pela sensibilização dos cidadãos, conferindo-the competências em relação à forma como atuar, antes, durante, e após o terramoto. De forma indireta, estes ficarão ainda potencialmente mais cooperativos com as medidas a tomar pelos serviços de emergência e recuperação, aumentando assim a eficácia das suas ações. Ao contrário de países onde a frequência sísmica é mais elevada e onde, em consequência, a implementação de estratégias de sensibilização, preparação e comunicação do risco se encontram naturalmente mais consolidadas, em países com reduzida memória histórica deste tipo de fenómenos, conseguir a atenção dos cidadãos para a importância da implementação de medidas de mitigação, gestão e comunicação do risco é uma tarefa bem mais complicada, mesmo quando a perigosidade sísmica associada é considerada de moderada a elevada, como é o caso de várias regiões de Portugal continental e do arquipélago dos Açores. Efetivamente, a baixa magnitude da grande maioria dos eventos sísmicos ocorridos ao longo das últimas décadas em território continental têm contribuído decisivamente para a baixa perceção do risco de terramotos da população Portuguesa.

Assim, o presente artigo aborda e discute o papel da perceção e comunicação na mitigação do risco de terramoto com base num conjunto alargado de resultados obtidos através de uma campanha de sensibilização realizada no âmbito do projeto de investigação "URBSIS: Avaliação e Gestão do Risco Sísmico à Escala Urbana", coordenado pela Universidade de Aveiro. De forma genérica, o trabalho que aqui se apresenta consistiu na recolha e tratamento de um conjunto de respostas a um questionário elaborado com o objetivo de avaliar a perceção dos cidadãos para a problemática do risco de terramoto. Este questionário teve como público alvo os residentes do Bairro Ribeirinho da cidade de Faro e a comunidade técnica local ligada, direta ou indiretamente, aos setores da construção e do planeamento urbano.

\section{Sensibilização para o Risco}

Em sociedades frequentemente assoladas por desastres de origem natural ou humana, a implementação de estratégias e de ações de sensibilização, preparação, gestão e comunicação do risco encontra-se naturalmente facilitada (Kung e Chen, 2012). Pelo contrário, em sociedades com reduzida memória histórica e experiência em desastres, é mais difícil sensibilizar as populações da necessidade de implementar medidas efetivas de preparação, gestão e comunicação do risco.

Alguns exemplos de terramotos históricos marcantes em Portugal são o de 26 de janeiro de 1531 no Vale do Tejo, o
Grande Terramoto de Lisboa de 1 de novembro de 1755, o sismo de 11 de novembro de 1858 ocorrido a sul de Setúbal, o sismo de Benavente de 23 de abril de 1909, o sismo de 28 de fevereiro de 1969, com uma magnitude de $7.4\left(M_{w}\right)$ e epicentro a sudoeste de Portugal continental, e, mais recentemente, os terramotos ocorridos no arquipélago dos Açores em 1980 e 1998. O Grande Terramoto de Lisboa, que atingiu uma magnitude estimada entre os 8.5 e os 9.0 na escala de Ritcher, foi amplamente reportado na época, e continua nos dias de hoje a ser um dos maiores, senão mesmo o maior, evento sísmico deste tipo registado na história do continente europeu.

Sucedido por um enorme tsunami, com ondas entre 5 e 10 metros, e por violentos incêndios, este evento deixou um enorme rasto de destruição na cidade de Lisboa, que ficou praticamente destruída. A costa sul do país foi também ela bastante afetada, incluindo a região do Algarve. Com um total de vítimas mortais estimado entre 10,000 e 100,000, este é tido como um dos eventos sísmicos mais mortíferos da história. Em termos económicos, este foi também um dos maiores desastres financeiros da história da Europa Ocidental, com uma perda financeira estimada entre $32 \%$ e $48 \%$ do produto interno bruto Português (Pereira, 2009). Pese embora a severidade deste evento em particular, a atual atividade sísmica do território continental Português é maioritariamente latente, sendo caracterizada por pequenos abalos espaçados no tempo, e de muito baixa intensidade.

Embora a percepção para o risco depende de inúmeros fatores, poder-se-á dizer que a percepção para um determinado risco surge da conjugação da ocorrência de um evento forte, com uma elevada probabilidade de retorno num curto espaço de tempo. Assim, e apesar da probabilidade e da frequência da ocorrência de fenómenos sísmicos em Portugal possa ser considerada moderada a elevada, a grande maioria dos eventos sísmicos ocorridos ao longo das últimas décadas foram de baixa magnitude (inferiores a 5.0 na escala de Richter), facto que contribuiu decisivamente para a baixa percepção do risco de terramoto por parte da população portuguesa. Importa, no entanto, ressalvar o caso do arquipélago do Açores onde existe já uma cultura sísmica devidamente estabelecida e enraizada, decorrente de uma atividade sísmica mais frequente e do registo de magnitudes mais elevadas (superiores a 5.0 na escala de Richter).

\section{Programas de Educação e Formação para o Risco}

Apenas com base na promoção de programas de educação e sensibilização é possível capacitar a população para a necessária perceção do risco. No caso concreto da cidade Italiana de Veneza, esta vertente da educação, formação e perceção pública 
dos riscos tem sido trabalhada através de campanhas de consciencialização pública e de educação a todos os níveis de qualificação escolar. A incorporação deste tópico nos currículos escolares e nas ações de informação motivará a médio prazo outros movimentos e associações com programas e objetivos na construção de comunidades mais resilientes. No Japão, as crianças em idade pré-escolar são recetoras de formação e informação de como reagir e atuar em caso de sismo. As autoridades japonesas alegam que este investimento salvou imensas vidas nos sismos mais recentes.

A educação e formação são fundamentais na preparação de entidades públicas, tais como polícia, bombeiros, autoridades municipais, equipas médicas, professores, entre outros, na resposta em caso de desastre. As organizações não governamentais (NGOs) são também entidades com importante papel nas operações pósterramoto. Deve existir um programa de formação atualizada e com uma periocidade anual que contemple eventos nacionais de consciencialização para o risco de terramoto, como sucede no caso de muitos países que sofreram perdas humanas e económicas devastadoras.

A preparação para o sismo passa em primeiro lugar pela sensibilização da população, não apenas porque esta poderá estar melhor preparada para agir, antes, durante, e após o terramoto, mas também porque será potencialmente mais cooperativa com as medidas a tomar pelos serviços de emergência e recuperação, aumentando assim a eficácia das suas ações. Este aspeto terá necessariamente de corresponder a uma longa e persistente campanha de informação transversal a várias áreas funcionais da sociedade da designada "roda da resiliência" (fig. 1), uma vez que, contrariamente ao que sucede em países frequentemente atingidos por terramotos, a ausência de eventos com impacto significativo em Portugal continental nas últimas décadas, tende a induzir um relaxamento natural nos níveis de preocupação e de prevenção da população em geral.

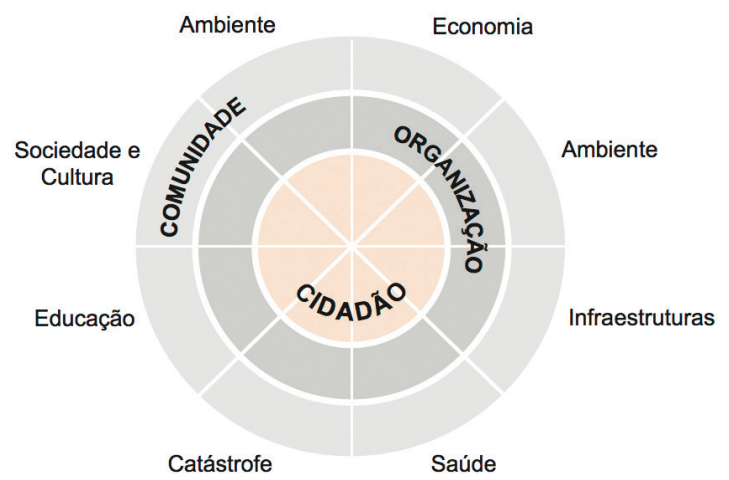

Fig. 1 - Roda da resiliência.

Fig. 1 - Resiliency wheel.

\section{Perceção do Risco de Terramoto em Portugal}

A análise da percepção do risco de terramoto em Portugal é essencial para a definição de um plano de comunicação do risco apropriado. Esse plano deve abordar a atual percepção do risco e da perigosidade sísmica da população residente no território continental Português e no arquipélago dos Açores.

Um dos paradoxos mais interessantes na literatura sobre percepção do risco de terramoto é que os riscos que matam e amedrontam as populações, e os riscos que as alarmam são, frequentemente, muito diferentes (Covello, 2010). Isto é, os riscos que mais preocupam e incomodam as pessoas não apresentam geralmente grandes consequências. Paralelamente, existem alguns riscos que matam ou que causam danos elevados, mas que preocupam e incomodam pouco as pessoas. Este paradoxo é explicado em parte por fatores que afetam a forma como os riscos são percepcionados (Covello, 2010). Essa percepção determina a resposta emocional das populações à informação do risco. Níveis de medo, preocupação, ansiedade, raiva ou indignação tendem a ser inferiores quando um determinado risco é percepcionado e compreendido pelas populações, e relativamente bem caracterizado pela ciência. Todos estes fatores contribuem para reduzir a consciência das populações para o risco de terramoto.

A consciência e a percepção do risco não dependem unicamente da experiência e da memória pessoal de exposição ao risco. Uma outra forma de desenvolver consciência de risco e de moldar a percepção pessoal é através da criação e disseminação de informação, da utilização de ferramentas de comunicação e da organização de campanhas de percepção de risco. Note-se que algumas instituições Portuguesas têm sido bastante ativas neste campo. Como exemplo refira-se que a Autoridade Nacional para a Proteção Civil (ANPC) organizou recentemente uma ação com o objetivo de incrementar a percepção e a preparação da população em caso de risco de terramoto. A primeira edição da ação "A terra treme" decorreu a 11 de outubro de 2013 e pretendeu informar a população acerca de como reagir em caso de terramoto.

\section{O Projeto URBSIS}

Em agosto de 2010 foi publicado uma Resolução da Assembleia da Republica para a adoção de medidas para a redução de risco sísmico, que promova a investigação científica neste domínio, incentivando um plano nacional de redução da vulnerabilidade sísmica. De entre inúmeras recomendações feitas, refira-se o estímulo à investigação científica nas áreas da avaliação e gestão do risco de terramoto e a promoção, junto das autarquias e com apoio dos serviços do Estado do meio técnico e 
científico local, a elaboração de cartas de risco de terramoto que identifiquem as zonas e as tipologias de edifícios mais vulneráveis.

É precisamente no contexto deste documento que surge o projeto de investigação "URBSIS: Avaliação e Gestão do Risco Sísmico à Escala Urbana”, coordenado pela Universidade de Aveiro (UA) em parceria com o Instituto Superior Técnico (IST) de Lisboa, e com o apoio institucional das Câmaras Municipais de Aveiro, Faro e Horta, na ilha do Faial, Açores. O projeto contou ainda com a parceria da Associação para a Comunicação do Risco e da Gestão de Crise (ACRGC), a congénere nacional da International Association of Risk and Crisis Communication (IARCC). A IARCC é uma associação não governamental independente com sede em Genebra, na Suíça, formada por uma rede de associações nacionais. O objetivo da IARCC e das suas organizações nacionais é o aprofundamento da comunicação responsável e profissional e o seu reconhecimento como uma ferramenta importante na redução dos riscos e dos seus efeitos em termos de perdas e na prevenção de situações de crise e de catástrofe. A IARCC, apoiada pelas suas associações nacionais, constitui-se como uma plataforma para todos os intervenientes de qualquer projeto relacionado com a problemática do risco e da comunicação de crise.

Com inicio executivo em julho de 2013 e fecho em dezembro de 2015, do projeto URBSIS resultaram um conjunto de outputs científicos e recomendações técnicas que visam contribuir para melhorar o entendimento e a percepção do risco, não apenas da comunidade científica, técnica e política, mas igualmente do público em geral. Esta componente da comunicação do risco veio ao encontro dos objetivos definidos previamente pela equipa científica do projeto, os quais passavam por, nomeadamente: garantir a boa cooperação com as populações de dos núcleos em estudo (Faro, Faial e Aveiro) e seus representantes; garantir que o conteúdo da audição pública preparada pela equipa é compreendida pelas populações e que, em consequência desta, são definidas, planeadas e implementadas ações consonantes com os seus resultados; melhorar a estratégia de comunicação do risco e da crise e o planeamento de emergência no caso da ocorrência de um terramoto; reforçar o seu nível de preparação e as suas capacidades globais de gestão de riscos.

\section{Metodologia de Comunicação Associada ao Projeto}

De forma a definir o plano de comunicação de risco mais adequado, é necessário considerar de forma cuidadosa todos os aspectos subjacentes à comunicação. Um aspeto fundamental reside na definição clara dos princípios básicos e das linhas orientadoras relacionadas com o planeamento urbano, com a arquitetura e com as infraestruturas. Estas bases deverão ainda ser acompanhadas do conhecimento do estado da arte das ciências da sismologia e da engenharia sísmica. Encontrando-se os decisores e as comunidades familiarizadas com estes fundamentos, o passo seguinte será definir e implementar regras que reflitam tais fundamentos e standards. Tal como ilustrado na fig. 2, o Nível A define "O que tem de ser feito" e o Nível B define "como deve ser feito". Assim que estas definições estejam claras, os atores responsáveis poderão dar então inicio ao processo de comunicação e informar todos os intervenientes. Este processo de comunicação necessita de uma estratégia, na qual é definido o objetivo, a mensagem, o púbico alvo e as ferramentas (Nível C). A estratégia de comunicação será a base do plano de comunicação do risco, através da qual são definidos os elementos adicionais que permitem responder às seguintes questões essenciais: "Que ações e atividades devemos pôr em prática?”; "Quem será o responsável por essas ações?”; “Em que momento é que a comunicação terá lugar?”; "Qual será o orçamento para determinada atividade?", e "Com base em que critério(s) podemos classificar uma campanha de comunicação bem sucedida?".

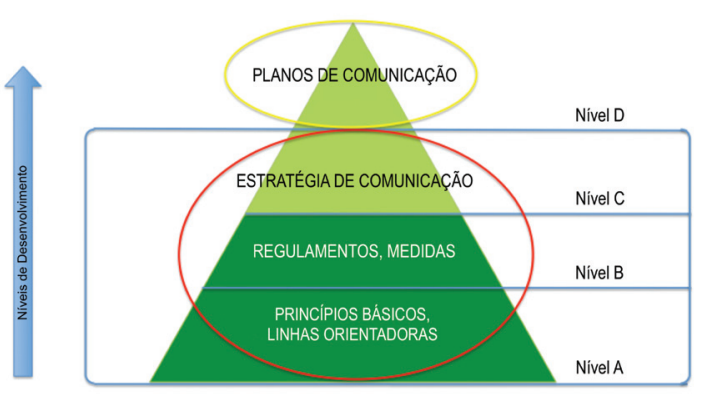

Fig. 2 - Pirâmide da comunicação.

Fig. 2 - Communication pyramid.

\section{Perceção do Risco de Terramoto em Portugal: Questionário e resultados}

A percepção do risco é uma questão chave na definição e adoção de medidas preventivas. De forma a desenvolver medidas efetivas de informação e comunicação do risco, a percepção do risco e os fatores que a influenciam devem ser conhecidos. Com esse intuito, no âmbito do projeto URBSIS foi elaborado e tornado público um questionário de percepção de risco, questionário esse cujos resultados são apresentados e discutidos nas seções seguintes.

A partir da informação recolhida e tratada, é notória a falta de entendimento dos inquiridos relativamente à questão da percepção do risco de terramoto. Mais, tendo em conta que a grande maioria dos inquiridos reside na região do Algarve, uma das regiões que apresenta maior perigosidade sísmica em Portugal continental, esta falta generalizada de entendimento sobre conceitos como vulnerabilidade, perigosidade, exposição e 
risco é particularmente grave e preocupante, sendo naturalmente merecedora de uma maior atenção. Assim, pela interpretação dos resultados, verifica-se claramente a urgência de tomar medidas no sentido de melhorar a comunicação do risco de terramoto em Portugal.

\section{O Questionário}

Com o objetivo explorar o nível de percepção e comunicação da população, foi criado um questionário público para avaliar o seu conhecimento em relação aos fenómenos sísmicos e o seu grau de preparação e resposta em caso de ocorrência de um terramoto. Assim, elaborou-se um conjunto de questões básicas relacionadas com a atividade sísmica, com as características do edificado, acerca de como proceder em caso de terramoto e sobre quem é responsável por coordenar as ações de reposta. Tal como foi já referido, este questionário foi pensado para avaliar o nível de conhecimento relativo ao risco de terramoto, e por isso foram preparadas duas versões: a primeira versão para a comunidade técnica (engenheiros, arquitetos, decisores políticos, etc.) e a segunda versão para o público em geral. Note-se que este artigo aborda apenas os resultados obtidos através do questionário para o público em geral.

O questionário foi realizado através de entrevista de rua aos residentes do núcleo urbano antigo de Faro e encontra-se atualmente online com o objetivo de alargar, tanto o número de questionários preenchidos, com o universo dos inquiridos. A fig. 3 apresenta o layout geral do questionário.

Importa acrescentar que a amostra é composta por 135 indivíduos, 72 dos quais do sexo masculino, e os restantes 63 , do sexo feminino. A maioria dos inquiridos encontrase na faixa etária entre os 25 e os 50 anos $(72.22 \%$ e $66.66 \%$ dos homens e das mulheres, respectivamente). Relativamente ao nível de instrução dos inquiridos, $79.17 \%$ dos homens e $90.48 \%$ das mulheres apresentam formação média ou superior (65 indivíduos, o que representa cerca de $48.15 \%$ do total da amostra).

\section{Exposição e Discussão dos Principais Resultados}

Os resultados obtidos através do tratamento dos resultados do questionário exposto na fig. 3 encontram-se apresentados e discutidos na presente secção. Com o objetivo de facilitar a sua análise, estes encontramse divididos em quatro grandes grupos: memória da população em relação a eventos sísmicos passados; conhecimento geral acerca da atividade sísmica em Portugal; comportamento sísmico adequado de pessoas e edifícios e, capacidade de resposta face a um terramoto (cada um deles tratado graficamente nas fig.s 4 a 7).

Da análise da fig. 4(a) é possível constatar que a grande maioria dos inquiridos (84\%) reportam já ter sentido pelo menos um sismo ao longo da sua vida. Os restantes $16 \%$ afirmam nunca ter experienciado um terramoto. Esta é uma observação interessante uma vez que, de acordo com o Instituto Português para o Mar e a Atmosfera (IPMA, IP), o território Português é atingido com uma frequência quase diária por pequenos abalos de baixa magnitude, alguns deles passiveis de serem sentidos pela população.

A segunda questão, ver fig. 4(b), revela que 56\% dos inquiridos assumem nunca ter participado em ações informativas sobre terramotos. Tais iniciativas são fundamentais para instruir as populações sobre conceitos básicos relacionados com os fenómenos sísmicos e acerca de como devem proceder durante e após um evento. Recentemente, vários países, tais com a Turquia e a Itália, têm vindo a promover um investimento proativo na educação para o risco de terramoto, nomeadamente através de programas de sensibilização e prevenção e da publicação de manuais práticos (Elgin, 2009).

Em relação à terceira e última questão deste primeiro grupo de respostas, apesar de mais de $56 \%$ dos inquiridos assumir nunca ter participado em ações informativas, $13 \%$ e $47 \%$ dos entrevistados consideram possuir um nível de conhecimento bom e suficiente, respetivamente, em relação a esta matéria. No entanto, 36\% dos inquiridos consideram possuir um nível de conhecimento insuficiente ou inadequado.

O segundo grupo de questões, ilustrado na fig. 5, é dedicado à análise do conhecimento geral da população acerca da atividade sísmica em Portugal, quer no que se refere à memória de eventos passados, quer no que respeita ao risco de terramoto da cidade de Faro.

O objetivo da primeira questão foi avaliar a memória dos inquiridos em relação a eventos sísmicos importantes ocorridos em Portugal, isto é, eventos passados responsáveis por mortes ou por prejuízos materiais avultados. Importa referir que, uma vez que estamos a considerar todo o território nacional, a reposta correta seria: no Arquipélago dos Açores, remetendo para o sismo ocorrido nas ilhas do grupo central no ano de 1998. No entanto, e uma vez que este inquérito foi realizado apenas a nível local, a resposta Algarve foi também ela considerada correta, uma vez que o sismo de 1969 provocou danos severos na região. 65\% dos inquiridos recorda o grande terramoto de Lisboa, em 1755, como sendo o último grande sismo ocorrido em Portugal, seja por falta de memória de eventos posteriores ou por considerarem que este foi efetivamente o terramoto mais devastador alguma vez sentido em Portugal e um dos mais importantes a nível mundial.

Quanto à segunda questão deste grupo, importa referir que os terramotos, enquanto desastres naturais, ocorrem usualmente devido a duas causas principais, são elas, a interação entre placas tectónicas e a atividade vulcânica. 
A partir do resultado apresentado na fig. 5(b), é evidente que a esmagadora maioria dos inquiridos, cerca de $92 \%$, associa a atividade sísmica em Portugal à tectónica de placas. Apenas cerca de $3 \%$ dos inquiridos acredita que a atividade vulcânica é responsável por alguma atividade sísmica concentrada em certas zonas do território nacional, nomeadamente no arquipélago dos Açores. Finalmente, 5\% dos inquiridos respondeu de forma incorreta, considerando que os fenómenos de aquecimento global são os responsáveis pela atividade sísmica em Portugal.

Nome
Indique o seu primeiro e último nome.

Sexo *

Masculino

Feminino

Idade *

$\bigcirc<18$

$18-24$

$25-34$

$35-50$

$\bigcirc>50$

Habilitações Académicas *

Indique apenas a mais recente habilitação.

$1^{\circ}$ e/ou $2^{\circ}$ ciclo

$3^{\circ}$ ciclo

Ensino secundário

Licenciatura

Mestrado

Doutoramento

Área de Actividade Profissional *

Alguma vez participou ou assistiu a algum evento de esclarecimento ou perceção sobre eventos sismicos?

Sim

Não

Já sentiu algum evento sísmico? *

$\mathrm{Sim}$

Não

Como classifica o seu nivel de conhecimento sobre fenómenos sísmicos? *

$\square$ Excelente

$\square$ Bom

$\square$ Suficiente

$\square$ Insuficiente

Desconhece por completo

Acredita que o perigo de tsunami possa estar associado ao risco sísmico no Algarve? *

Sim

Não

Sem opinião

Qual(quais) dos seguintes procedimentos deve adotar durante um sismo, caso se encontre no interior de um edificio? *

Baixar, proteger e aguardar

Evacuar de imediato o edifício

$\checkmark$ Procurar abrigo sob mesas ou outros vãos

Dirigir-se imediatamente para a divisão mais pequena do edifíicio

$\square$ Nenhuma das respostas anteriores

Conhece as causas que estão na origem dos sismos ocorridos em Portugal? *

$\square$ Aquecimento global

Movimento das placas tectónicas

$\square$ Atividade vulcânica

Qual foi a região afetada pelo último grande evento sísmico que ocorreu em Portugal? *

Q

Como classifica o risco sísmico do território nacional? *

Atribua uma classificação média para todo o território.

Muito elevado

Elevado

Moderado

Baixo

Muito baixo

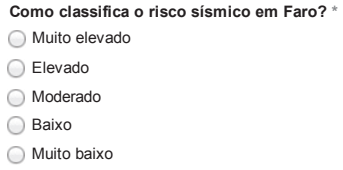

Muito elevado

Elevado

Moderado

Baixo

Muito baixo

A região de Bragança apresenta maior risco sísmico que Faro? *

$\mathrm{Sim}$

Não

Globalmente, como classifica a capacidade dos edifícios em Faro para resistir a um eventual

Excelente

Bom

Suficiente

Insuficiente

Desconhece

Edifícios mais altos são de uma maneira geral mais seguros que os edifícios mais baixos? *

Sim

Não

Sem relação

A segurança estrutural dos edifícios face à ação sísmica está apenas relacionada com a qualidade dos respetivos materiais de construção? *

Sim

Não

Não sei

A definição de vulnerabilidade sísmica está relacionada com qual(quais) dos seguintes

$\square$ Características geométricas e mecânicas dos edifícios

$\square$ Região geográfica onde o edificio está inserido

Histórico de ocorrências sísmicas do pais

Sente que o país está preparado para responder a uma situação de emergência sísmica? *

Sim

Não

Acredita que num futuro próximo ( 50 anos) a cidade de Faro possa ser atingida por um sismo semelhante ao de Lisboa de 1755 ? *

Sim

Não

Acha necessário um sistema de certificação sísmica de edifícios novos e a reabilitar em Portugal? *

Sim

Não

Na sua opinião, quem é a entidade responsável pela salvaguarda da sua segurança, na eventualidade de uma ocorrência sísmica? *

O governo

A proteção civil

As câmaras municipais

As companhias de seguros

Nenhuma das respostas anteriores

Muito obrigado pela sua participação neste estudo. *

Respondi atentamente ao questionário e pretendo submeter as minhas respostas.

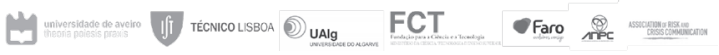

Submit

Never submit passwords through Google Forms.

Fig. 3 - Inquérito à população sobre perceção e nível de conhecimento sobre sismos.

Fig. 3 - Questionnaire on perception and communication of seismic risk. 
territorium 25 (II)
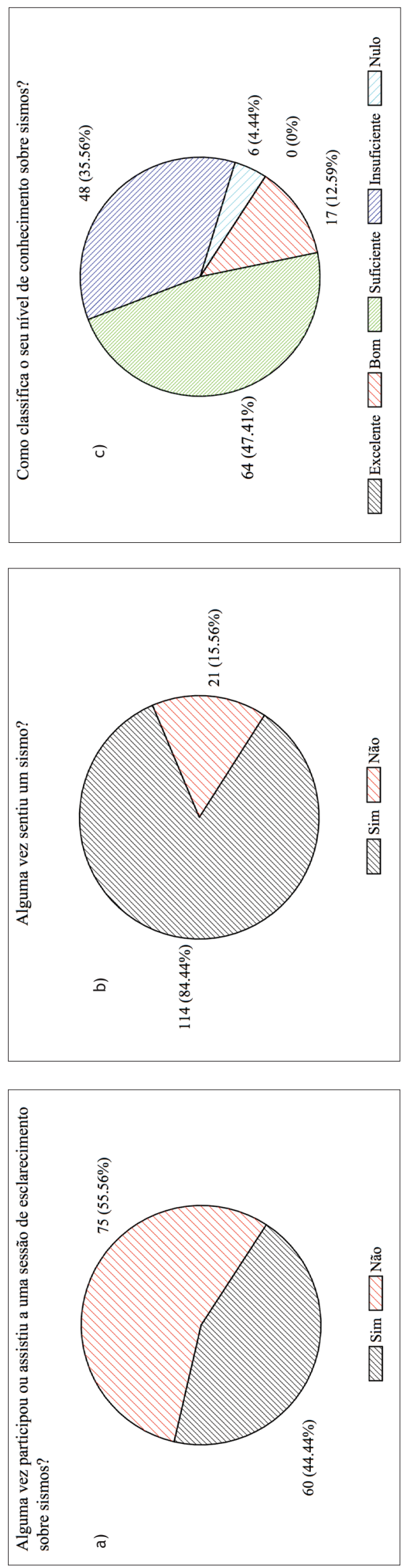

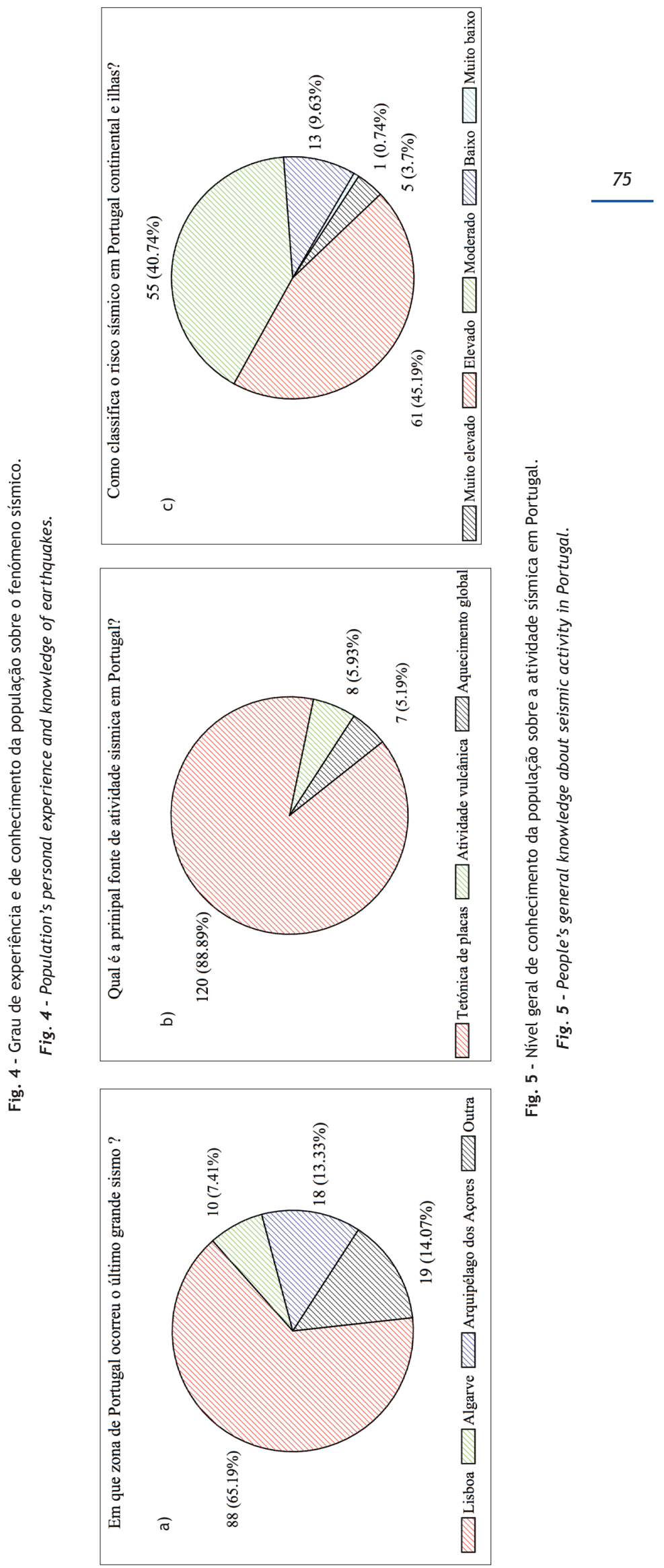


A terceira questão foi formulada com o objetivo de avaliar a opinião dos inquiridos em relação ao risco sísmico associado ao território Português (continental e ithas). De acordo com o resultado obtido, cerca de $86 \%$ dos inquiridos classificam o risco de terramoto associado ao território nacional como moderado a elevado, enquanto $4 \%$ classificam esse risco como sendo muito elevado e os restantes $10 \%$ baixo a muito baixo. Apesar da ambiguidade inerente a esta questão, vale a pena sublinhar a aparente consciência da grande maioria dos participantes, que classificaram o risco de terramoto em Portugal entre moderado e elevado.

De seguida, a fig. 6 apresenta as respostas obtidas para as questões formuladas com o objetivo de obter a opinião dos inquiridos em relação à forma como as pessoas devem reagir e se os seus edifícios estão, ou não, preparados estruturalmente para resistir a um evento sísmico. Para a questão ilustrada na fig. 6(a) deve salientar-se que, considerando um edifício corrente, duas respostas podem ser consideradas corretas: "Proteger-se, baixar-se e aguardar" e "Proteger-se sob uma mesa ou sob um vão de porta". Assim, e no total, cerca de $58 \%$ dos inquiridos escolheram uma destas opções. No que respeita às respostas incorretas, 20\% dos participantes acredita que evacuar o edifício de forma imediata é a decisão mais acertada. A propósito desta ideia é importante recordar que muitos dos eventos sísmicos mais destrutivos ocorridos no passado provaram que este comportamento deve ser evitado uma vez que a queda de objetos pesados, nomeadamente de elementos não estruturais dos edifícios, tem sido uma das principais causas de vítimas (T. M. Ferreira et al., 2014). Globalmente, cerca de $42 \%$ dos inquiridos desconhecem as recomendações básicas de segurança a adoptar em caso de terramoto.

No que respeita à opinião dos inquiridos acerca da capacidade dos edifícios de Faro para resistir a um eventual evento sísmico, na fig. 6(b), a grande maioria dos participantes, cerca de $67 \%$, não tem dúvidas em classificá-la como insuficiente, tendo por base o mau estado geral deste edificado, particularmente dos edifícios localizados no núcleo urbano antigo da cidade, onde a percentagem de edifícios devolutos é muito elevada (ver Maio et al., 2015). Ainda assim, $21 \%$ dos inquiridos acredita que, de uma forma geral, o edificado da cidade de Faro apresenta resistência sísmica adequada e que por isso será capaz de resistir a um eventual evento sísmico sem danos significativos. Finalmente, 10\% dos participantes afirmam desconhecer a vulnerabilidade sísmica dos edifícios da cidade de Faro.

A última questão deste grupo pretende avaliar o nível de conhecimento da população acerca do conceito de vulnerabilidade. Como é sabido, a vulnerabilidade sísmica de uma estrutura pode ser descrita como uma propriedade intrínseca dessa estrutura e que reflete a sua predisposição para sofrer dano devido a uma determinada ação sísmica encontrando-se por isso associada às suas características físicas e estruturais. (Barbat et al., 2010; Tiago Miguel Ferreira et al., 2013). Como pode ser observado na fig. 6(c), apenas $33 \%$ dos inquiridos reconhece este conceito e conhece a definição correta de vulnerabilidade sísmica. As restantes respostas encontram-se distribuídas entre os inquiridos que acreditam que a localização geográfica do edifício influencia a sua vulnerabilidade sísmica (cerca de $40 \%$, aqueles que consideram que a história de ocorrência sísmicas em Portugal é um fator decisivo na sua vulnerabilidade (4\%) e aqueles que consideraram, de forma incorreta, mais do que um destes fatores (19\%).

Finalmente, o quarto conjunto de questões pretende avaliar a percepção dos cidadãos em relação à preparação de Portugal para fazer face a um evento sísmico e sobre o papel das autoridades numa situação de catástrofe (ver fig. 7).

Pese embora na maioria das questões anteriores as respostas não tenham sido alarmantes, quando questionados sobre a preparação de Portugal para fazer face a um evento sísmico, 95\% dos inquiridos não acredita que o nosso país esteja preparado para responder a tal desafio. A ineficácia ou a ineficiente divulgação dos planos estratégicos de resposta em caso de catástrofe, a sua lenta implementação e até alguma negligência política, têm contribuído decisivamente para a criação desta imagem negativa.

Ultimamente esta questão tem gerado alguma controvérsia em Portugal a propósito da criação e implementação de uma certificação sísmica do edificado novo e existente. Vários especialistas nacionais desta área têm vindo a defender que proprietários e inquilinos devem ter consciência da resistência sísmica e da qualidade estrutural e sísmica do edifício onde habitam. Para tal, e à semelhança da certificação energética já existente em Portugal, a comunidade científica da especialidade e a Sociedade Portuguesa de Engenharia Sísmica (SPES) propõem um sistema de certificação equivalente para a questão da resistência sísmica. Esta medida, que seria de extrema utilidade para o mercado segurador, tem sido debatida de forma acesa e encontra-se atualmente a aguardar acordo político. 0 ponto de vista dos inquiridos em relação a este assunto é claro, com $86 \%$ destes a considerar que se exige um sistema de certificação sísmica, tanto para edifícios novos, como para edifícios existentes. Finalmente, $75 \%$ dos entrevistados está consciente de qual a autoridade nacional responsável por assegurar a segurança da população durante e após um terramoto. Apenas $20 \%$ dos inquiridos atribui essa competência ao governo, o que é de certa forma compreensível, uma vez que é sobre o governo central que recai a responsabilidade de definir a estratégia nacional. 
territorium 25 (II)
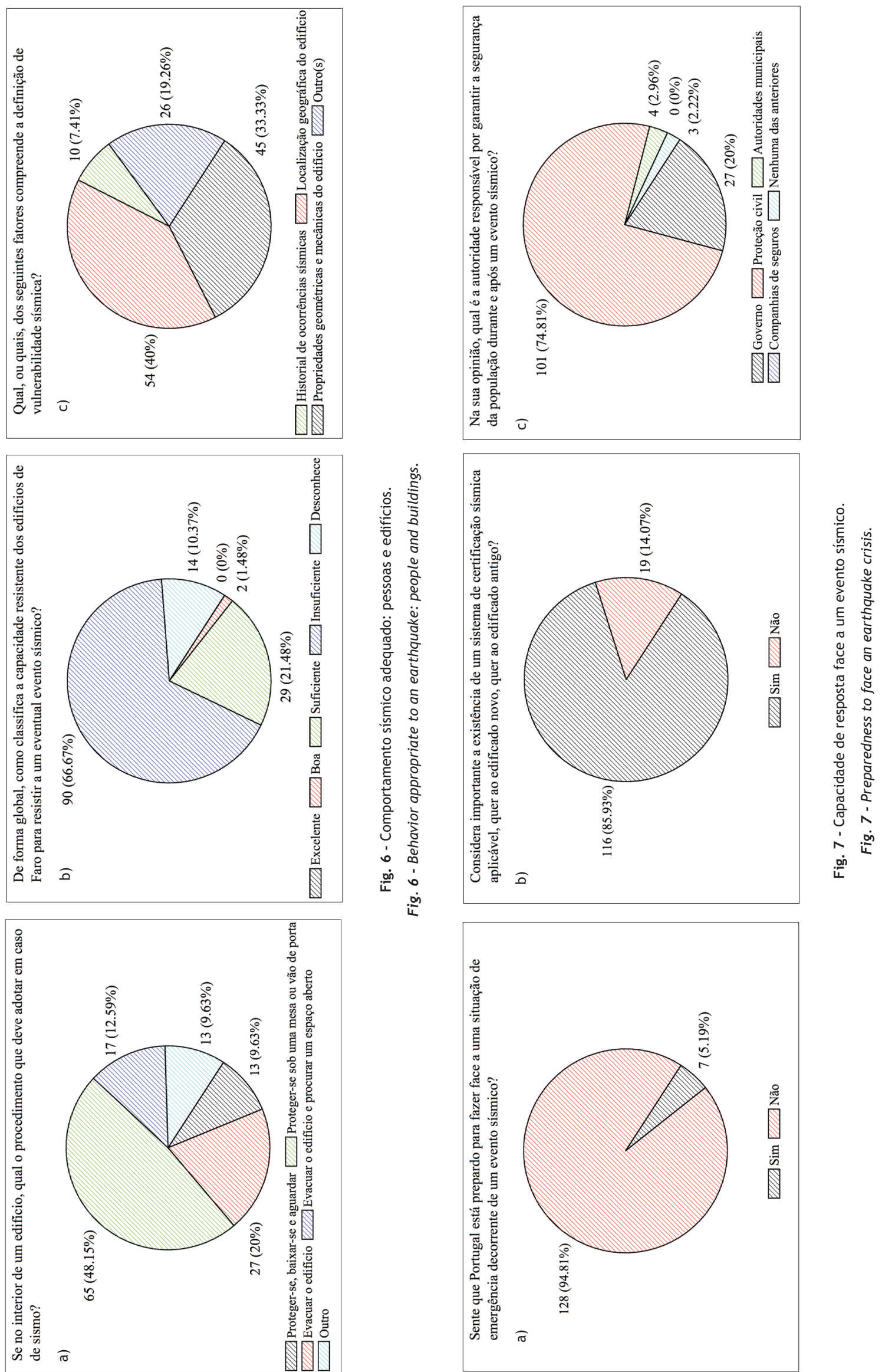
Uma pequena percentagem das pessoas inquiridas, cerca de $5 \%$, desconhece completamente qual a autoridade nacional responsável por este assunto.

\section{Conclusões}

Este artigo aborda o papel da perceção e comunicação na mitigação do risco de terramoto com base na discussão de um conjunto alargado de resultados obtidos através de uma campanha de sensibilização e recolha de informação realizada no âmbito do projeto de investigação "URBSIS: Avaliação e Gestão do Risco Sísmico à Escala Urbana”, os quais permitiram avaliar o nível de perceção dos residentes no Bairro Ribeirinho da Cidade de Faro para a temática. Segundo foi possível apurar com este trabalho, a percepção desta comunidade em relação ao risco de terramoto e à sua mitigação é insuficiente. Para combater esta situação, e à semelhança do que tem vindo a ser feito em vários países através da implementação de projetos à escala nacional, a realização de campanhas de informação e educação para o risco sísmico deverão ser tidas como prioritárias. De entre os vários projetos passíveis de serem referenciados aqui, refira-se o National Earthquake Hazards Reduction Program (NEHRP) e o Istanbul Seismic Risk Mitigation and Emergency Preparedness Project (ISMEP), ambos com a especificação de linhas de atuação nas áreas da percepção, educação e comunicação do risco de terramoto. Uma referência especial ao UNISDR pelo desenvolvimento do guia "My city is getting ready", um documento lato mas que define algumas das principais bases de ação e estratégia.

Há ainda muito trabalho a fazer, a vários níveis, pelas autoridades nacionais, nomeadamente: a realização de cursos técnicos de prevenção de desastres e emergência; reforço da educação, através do desenvolvimento e da implementação de mecanismos e protocolos com o objetivo de minorar os efeitos dos desastres naturais; realização de campanhas públicas de informação ao nível das cidades, tendo em vista a educação das população para as problemáticas do risco, nomeadamente em relação à prevenção e ao comportamento em caso de catástrofe.

Uma vez que se pretende que este estudo seja alargado a outras cidades, o conteúdo do questionário aqui apresenta- do será refinado e a sua disseminação melhorada. As questões deverão procurar avaliar o impacto direto que este tipo de eventos teve ou tem na vida das pessoas, sendo que as questões abertas deverão dar a possibilidade ao inquirido de propor eventuais medidas de melhoria. Na fase final deste estudo, a análise conjunta de todas as questões deverá dar indicações valiosas sobre como deverá ser produzida informação relacionada com o risco de terramoto e sobre a forma como essa informação deve ser comunicada, situação que tem sido pouco trabalhada pelas autoridades competentes, tal como testemunha o questionário realizado. Estes resultados permitirão ainda enriquecer a discussão em torno dos princípios básicos, das linhas orientadoras e dos procedimentos e regras relacionadas com a problemática do risco de terramoto em Portugal.

\section{Agradecimentos}

Este trabalho foi financiado pela Fundação para a Ciência e a Tecnologia (FCT) ao abrigo do projeto de investigação URBSIS: Avaliação da Vulnerabilidade e Gestão do Risco Sísmico à Escala Urbana (PTDC/ECM-URB/2564/2012).

\section{Bibliografia}

Barbat, A. H., Carreño, M. L., Pujades, L. G., Lantada, N., Cardona, O. D. and Marulanda, M. C. (2010). Seismic vulnerability and risk evaluation methods for urban areas. A review with application to a pilot area. Structure and Infrastructure Engineering, 6(1-2), 1738. DOI: https://doi.org/10.1080/15732470802663763

Covello, V. T. (2010). Strategies for overcoming challenges to effective risk communication. (R. L. Heath \& H. D. O'Hair, Eds.) Handbook of Risk and Crisis Communication. Routledge.

Elgin, K. G. (2009). Istanbul Seismic Risk Mitigation and Emergency Preparedness Project (ISMEP). In Improving the Seismic Performance of Existing Buildings and Other Structures (pp. 1129-1140).

Ferreira, T. M., Vicente, R., Mendes da Silva, J. A. R., Varum, H. and Costa, A. (2013). Seismic vulnerability assessment of historical urban centres: case study of the old city centre in Seixal, Portugal. Bulletin of Earthquake Engineering, 11(5), 1753-1773. DOI: https://doi.org/10.1007/s10518-013-9447-2

Ferreira, T. M., Vicente, R. and Varum, H. (2014). Seismic vulnerability assessment of masonry facade walls: development, application and validation of a new scoring method. Structural Engineering and Mechanics, 50(4), 541-561.

DOI: https://doi.org/10.12989/sem.2014.50.4.541

Kung, Y.-W., and Chen, S.-H. (2012). Perception of Earthquake Risk in Taiwan: Effects of Gender and Past Earthquake Experience. Risk Analysis, 32(9), 1535-1546.

DOI: https://doi.org/10.1111/j.1539-6924.2011.01760.x

Maio, R., Ferreira, T. M., Vicente, R., and Estêvão, J. (2015). Seismic vulnerability assessment of historical centres: case study of the old city centre of Faro, Portugal. Journal of Risk Research.

DOI: https://doi.org/10.1080/13669877.2014.988285

Pereira, A. (2009). The Opportunity of a Disaster: The Economic Impact of the 1755 Lisbon Earthquake. The Journal of Economic History, 69(2), 466-499. DOI: https://doi.org/10.1017/S0022050709000850 